\title{
Postpartum hypertension
}

\author{
Kristina Powles MD, Shital Gandhi MD MPH
}

Cite as: CMAJ 2017 July 10;189:E913. doi: 10.1503/cmaj.160785

\section{1}

\section{Blood pressure should be measured three to six days after \\ delivery ${ }^{1}$}

Blood pressure normally peaks three to six days postpartum in both normotensive women and those with previous hypertension. ${ }^{1,2}$ Pain, drugs (e.g., nonsteroidal anti-inflammatory drugs [NSAIDs]), excess fluid administration or restoration of vascular tone to prepregnancy level may increase blood pressure. ${ }^{2,3}$ Women with pre-existing hypertension or preeclampsia should be monitored carefully postpartum, and NSAIDs should be avoided for pain control. ${ }^{1,4}$

\section{2}

\section{Onset of preeclampsia can be postpartum}

About $5.7 \%$ of cases of preeclampsia or eclampsia may present de novo in the postpartum period (up to six weeks), even without hypertension in pregnancy. ${ }^{5}$ These women often present with new-onset persistent headaches or visual changes. ${ }^{3} \mathrm{~A}$ high clinical index of suspicion is crucial (e.g., check blood pressure, perform urinalysis and consult obstetrics). Women with preeclampsia or eclampsia should be referred immediately to hospital for treatment with magnesium sulfate (usually intravenously), antihypertensive therapy and monitoring. ${ }^{1}$

\section{Treatment is recommended if high blood pressure is present} persistently (systolic $>140$ and/or diastolic $>90)^{1}$

A woman with postpartum hypertension who is asymptomatic with a blood pressure of less than $160 / 110 \mathrm{~mm} \mathrm{Hg}$ can be treated as an outpatient with drugs taken orally (Box 1). ${ }^{1}$ All women with postpartum hypertension should be examined for HELLP (hemolysis, elevated liver enzymes, low platelets) syndrome and other endorgan effects by using tests for total blood count, levels of creatinine and liver enzymes, and urinalysis. Drug dosage can be titrated down once blood pressure is less than $140 / 90 \mathrm{~mm} \mathrm{Hg}$ for at least 48 hours. ${ }^{3}$ (This recommendation is specific to the postpartum period and differs from the Canadian Hypertension Education Program guideline for treating hypertension.)

\section{Postpartum hypertension may persist for several weeks}

Gestational hypertension and preeclampsia (two common causes of persisting postpartum hypertension) usually resolve by 12 weeks. ${ }^{2,4}$ Beyond this period, clinicians should consider a secondary cause of hypertension, which can be found in up to $10 \%$ of cases, ${ }^{2}$ before establishing a diagnosis of essential chronic hypertension. Initial investigations include serum creatinine, electrolytes and urinalysis. ${ }^{1}$ Further investigations may be considered based on clinical features.

5 Postpartum hypertension can be treated safely during breastfeeding Although there are limited studies assessing neonatal effects of maternal antihypertensive treatment during breastfeeding, well-established understanding of pharmacokinetic principles has led to the acceptance of multiple antihypertensive drugs as safe for use (Box 1). ${ }^{4}$ Diuretics and angiotensin II receptor blockers are not recommended. ${ }^{2,4}$

\begin{tabular}{|c|c|c|}
\hline Drug† & Usual dosage & $\begin{array}{l}\text { Maximum } \\
\text { dosage }\end{array}$ \\
\hline Nifedipine XL & 20-30 mg daily & 60 mg b.i.d. \\
\hline Labetalol & 100-200 mg b.i.d. & 300 mg q.i.d. \\
\hline Methyldopa & 250-500 mg b.i.d. & 500 mg q.i.d. \\
\hline Enalapril & 5-10 mg b.i.d. & 10 mg b.i.d. \\
\hline \multicolumn{3}{|c|}{ 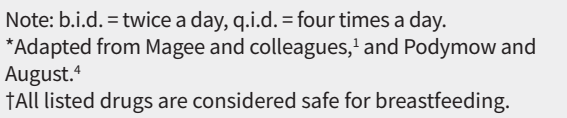 } \\
\hline
\end{tabular}

\section{References}

1. Magee LA, Pels A, Helewa M, et al.; Canadian Hypertensive Disorders of Pregnancy Working Group. Diagnosis, evaluation, and management of the hypertensive disorders of pregnancy: executive summary. J Obstet Gynaecol Can 2014;36:416-41.

2. Bramham K, Nelson-Piercy C, Brown MJ, et al. Postpartum management of hypertension. BMJ 2013; 346:f894.

3. Sibai BM. Etiology and management of postpartum hypertension-preeclampsia. Am J Obstet Gynecol 2012;206:470-5.

4. Podymow T, August P. Antihypertensive drugs in pregnancy. Semin Nephrol 2011;31:70-85.

5. Matthys LA, Coppage KH, Lambers DS, et al. Delayed postpartum preeclampsia: an experience of 151 cases. Am J Obstet Gynecol 2004;190:1464-6.

\section{Competing interests: None declared.}

This article has been peer reviewed.

Affiliations: Departments of Family and Community Medicine (Powles), and Medicine (Gandhi), Sinai Health System, Toronto, Ont.

Correspondence to: Kristina Powles, kristina. powles@sinaihealthsystem.ca 